\title{
The Effect of Balanced Hypocaloric Diet on the Anthropometric and Basic Metabolic Indicators in Infertile Women with Gluteofemoral Obesity
}

\author{
Natalia V. Artymuk², Natalia A. Sukhova², Olga A. Tachkova², Moamar Al-Jefout ${ }^{3,4,5,6}$ (1) \\ ${ }^{1}$ GA Ushakova Department of Obstetrics and Gynecology, Kemerovo State Medical University, Kemerovo, Russia \\ ${ }^{2}$ Hospital Therapy and Clinical Pharmacology Department, Kemerovo State Medical University, Kemerovo, Russia \\ ${ }^{3}$ The Department of Obstetrics \& Gynecology, College of Medicine and Health Sciences (CM \& HS), \\ United Arab Emirates University, Al-Ain, UAE \\ ${ }^{4}$ The Department of Obstetrics \& Gynecology, Tawam Hospital, Al-Ain, UAE \\ ${ }^{5}$ The Department of Obstetrics \& Gynecology, Faculty of Medicine, Mutah University, Karak, Jordan \\ ${ }^{6}$ The Department of Obstetrics and Gynecology, Sechenov First Moscow State Medical University (Sechenov University), \\ Moscow, Russia \\ Email: drmoamar@yahoo.co.uk
}

How to cite this paper: Artymuk, N.V., Sukhova, N.A., Tachkova, O.A. and AlJefout, M. (2019) The Effect of Balanced Hypocaloric Diet on the Anthropometric and Basic Metabolic Indicators in Infertile Women with Gluteofemoral Obesity. Open Journal of Obstetrics and Gynecology, 9, 1325-1335.

https://doi.org/10.4236/ojog.2019.910128

Received: September 15, 2019

Accepted: October 6, 2019

Published: October 9, 2019

Copyright $\odot 2019$ by author(s) and Scientific Research Publishing Inc. This work is licensed under the Creative Commons Attribution International License (CC BY 4.0).

http://creativecommons.org/licenses/by/4.0/

\section{cc) (i) Open Access}

\begin{abstract}
Purpose: To evaluate the effect of balanced hypocaloric diet therapy on the anthropometric and basic metabolic indicators in obese women with infertility. Methods: The follow up interventional clinical study included 23 infertile women in reproductive age with grade I gluteofemoral obesity. All patients have prescribed a balanced hypocaloric diet (1200 kcal/day), underwent exercise and behavioral therapy. Before and after 12-month treatment, an anthropometric study was conducted, determining the level of metabolic and hormonal indicators. Results: The total final number of study participants was 20 patients. A decrease in body weight was achieved in $87 \%$ of patients from 4 to $24 \mathrm{~kg}$, on the average, by $10.58 \pm 5.70 \mathrm{~kg}$, there was also a decrease in BMI from $32.53 \pm 1.40$ to $28.55 \pm 2.50 \mathrm{~kg} / \mathrm{m}^{2}$ ( $\left.\mathrm{p}<0.001\right)$. The decrease in body weight was accompanied by a statistically significant decrease in leptin levels $(p<0.001), E_{1}(p=0.049), E_{2}(p=0.032)$, fasting glucose $(p<0.001)$, HOMA-IR ( $\mathrm{p}=0.002)$, cholesterol $(\mathrm{p}<0.001)$, TG $(\mathrm{p}=0.004)$, LDL-C $(\mathrm{p}=$ $0.001)$, atherogenic index of plasma $(\mathrm{p}<0.001)$ and an increase in progesterone levels $(p=0.030)$. Ovulatory menstrual cycles were resumed in all women $(\mathrm{p}=0.007)$ and pregnancy occurred within a year in 1 patient. Conclusion: The implementation of a hypocaloric diet for 12 months in infertile women with first-degree obesity helps to normalize metabolic and hormonal indicators, reduces body weight and restores ovulatory menstrual cycle in all patients.
\end{abstract}




\section{Keywords}

Obesity, Reproductive Age, Infertility, Diet Therapy, Anovulation

\section{Introduction}

Currently, there is substantial evidence that obesity is a growing problem worldwide and is associated with serious health risks [1]. Obesity rises to the level of a global epidemic, and causes an increase in morbidity and mortality, both in adults and in children [2]. The role of obesity as a risk factor for atherosclerosis, dyslipidemia, diabetes, arterial hypertension, cardiovascular disease, stroke, gallstone disease, osteoarthritis, some cancers (breast, ovary, endometrium, large intestine), as well as infertility has been proved [3] [4]. There is currently no doubt that obesity is a risk factor for both maternal and perinatal deaths. Obesity is also a major risk factor for serious pregnancy complications: gestational diabetes, preeclampsia, premature rupture of membranes, fetal growth restriction, asphyxia, shoulder dystocia and the worrying increased numbers of cesarean sections [5].

Obese pregnant women have also a higher risk of fetal death, newborn asphyxia and early neonatal death. The offspring of obese women has a higher incidence of certain malformations, macrosomia, malnutrition, cerebral palsy, epilepsy, and neuropsychic developmental disorders [5] [6] [7].

There is growing evidence that obesity can develop in utero. For example, Sellayah D. [8] showed that mother's obesity contributes to an increase in the size of adipocytes in their offspring, but no increase in the number of adipocytes has been reported. A systematic review by Brown T. et al. [9], comprising 153 randomized clinical trials, showed that, for the prevention of obesity in children aged from 0 to 5 years, a combination of dietary interventions and physical activity are effective interventions, physical exercises have huge health advantages in children.

There is substantial evidence that obesity also affects reproductive potentials of women especially in those with PCOS resulting in infertility [10]. Many patients with PCOS demonstrate insulin resistance (IR), accompanied by compensatory hyperinsulinemia [11] [12] [13] [14]. In fact, insulin possesses true gonadotrophic function and an increased in insulin availability at the level of ovarian tissue may enhance excess androgen synthesis. Obesity, particularly the abdominal phenotype, may be partly responsible for insulin resistance and associated hyperinsulinemia in women with PCOS. Therefore, obesity-related hyperinsulinemia may play a key role in favoring hyperandrogenism [15] and increases the incidence of endometrial hyperplasia especially in women with oligomenorrhea and endometrial thickness $>9 \mathrm{~mm}$ [16]. Furthermore, insulin resistance is present not only in obese but also in non-obese women with PCOS. However, IR in non-obese women occurs in less frequency; Legro et al. [17] reported a higher 
prevalence of insulin resistance in obese (64\%) than in non-obese (20\%) women with PCOS.

Weight loss during pregnancy planning is an important intervention, both to address fertility issues and to prevent adverse maternal and perinatal outcomes, as well as to prevent metabolic and cardiovascular disease in the offspring of these women [1] [5] [18]. So, at present, an adequate diet and physical activity before and during pregnancy, as well as control of gestational weight gain and glucose level are considered mandatory procedures to reduce the risk of obesity in offspring [19].

Both medication [19] [20] [21] and the surgical approach can be effective in planning pregnancy for patients with obesity, especially with morbid obesity [22] [23]. However, the first basic measure for correcting body weight as part of pre-conceptional care is to prescribe a balanced hypocaloric diet in combination with exercise and correction of eating behavior using behavioral therapy [1] [5].

The aim of this study was to evaluate the dynamics of anthropometric, hormonal and metabolic parameters in infertile obese women with a balanced hypocaloric diet.

\section{Materials and Methods}

A prospective, interventional study was conducted at the M.A. Podgorbunsky Kemerovo City Clinical Hospital No. 3 in the city of Kemerovo-Russian Federation. The study design was approved by the Ethics Committee of the Kemerovo State Medical Academy. Informed consent was obtained from all individual participants included in the study. The study initially included 23 patients. Criteria for inclusion in the study: reproductive age (18 - 45 years), the presence of gluteofemoral obesity of the first degree (BMI $30-34.9 \mathrm{~kg} / \mathrm{m}^{2}$ ), anovulatory type of infertility. Exclusion criteria: age less than 18 and older than 45 years, other infertility factors (tubal, male and immunological factors), BMI less than 30 $\mathrm{kg} / \mathrm{m}^{2}$ and more than $34.9 \mathrm{~kg} / \mathrm{m}^{2}$, organic damage to the hypothalamic-pituitary region, adrenal glands (according to magnetic resonance imaging, computed tomography). Blood samples were taken from all participants after 12 - 14 hours fasting to determine the lipid profile and other hormonal levels before intervention and after 12 months.

All patients were prescribed balanced hypocaloric nutrition (1200 kcal/day) with physiological nutrient content: carbohydrates-50\%, proteins-20\%, fats$30 \%$ and fiber daily consumption of $30-40 \mathrm{~g}$ in dry form (grain and vegetables). Calorie distribution: breakfast-40\%, lunch-40\%, dinner-20\%. If necessary, 2 - 3 additional meals were allowed. Physical exercises: walking 1 - 2 hours a day at a speed of 120 steps per minute. Behavioral therapy to correct eating disorders: diary of food and lifestyle, motivational phone calls every week.

Before and 12 months after inclusion in the study, all patients underwent a standard survey with filling out a statistical map, a general clinical examination, an anthropometric examination: measuring height, body weight, waist circumference (WC) and hip circumference (HC). Body mass index (BMI) was calcu- 
lated by the formula: $\mathrm{BMI}=$ body weight $(\mathrm{kg}) /$ height $\left(\mathrm{m}^{2}\right)$. The severity of obesity was determined in accordance with the recommendations of WHO [24].

The nature of the distribution of fat was determined by calculating the ratio of $\mathrm{WC} / \mathrm{HC}$. The sagittal diameter (SD) was determined in the position of the subject on the back using a ruler, measuring the conditional perpendicular from the upper edge of the trunk at the level of the iliac crest to the surface on which the subject was lying $(\mathrm{cm})$. To calculate the indicators of fat volumes $(\mathrm{V}, \mathrm{l})$ and mass $(\mathrm{M}, \mathrm{kg})$ of total adipose tissue (TAT), visceral adipose tissue (VAT), subcutaneous adipose tissue (SAT) of anthropometric measurements the following formulas were used: VTAT $(\mathrm{l})=1.36 \times$ body weight $(\mathrm{kg}) /$ height $(\mathrm{m})-42.0$; VVAT $(\mathrm{l})$ $=0.731 \times \mathrm{SD}-11.5 ; \operatorname{VSAT}(\mathrm{l})=\operatorname{VTAT}(\mathrm{l})-\operatorname{VVAT}(\mathrm{l}) ; \operatorname{MTAT}(\mathrm{kg})=\operatorname{VTAT} \times$ 0.923; fat-free mass (FFM, $\mathrm{kg})=$ body weight $(\mathrm{kg})-\operatorname{MTAT}(\mathrm{kg})$.

The glycemic level in serum of capillary blood was determined by the glucose oxidase method (or the method of enzyme electrodes) on an empty stomach after 12 hours of fasting on an EXAN-G analyzer. Total cholesterol (cholesterol), triglycerides (TG), high-density lipoprotein cholesterol (HDL-cholesterol) were determined on an Express-550 biochemical multichannel analyzer, Ciba-Corning (Great Britain), after 16-hour fasting, using reagents Human (Germany), International Bio-Analytic Industries (USA). Total cholesterol was evaluated in the cleavage and oxidation reactions (using the peroxidase/phenol/n-amino-antipyrine system), triglycerides were determined after enzymatic hydrolysis with an enzymatic colorimetric test, and HDL-C using the precipitation method. Low-density lipoprotein cholesterol (LDL-C) and atherogenic index of plasma (AIP) were determined by the calculation method according to A. N. Klimov [25].

Hormonal studies were performed by enzyme-linked immunosorbent assay using standard kits Alkor Bio (Russia), Diagnostic system laboratories (DSL) (USA) in accordance with the instructions attached to the kits. The levels of luteinizing hormone ( $\mathrm{LH})$, follicle-stimulating hormone (FSH), prolactin (PRL), estrone $\left(\mathrm{E}_{1}\right)$, estradiol $\left(\mathrm{E}_{2}\right)$, and serum testosterone were studied on days 5 - 6 of the menstrual cycle, progesterone levels were evaluated on days 21 22 of the menstrual cycle. Determination of the content of leptin, immune-reactive insulin (IRI) was carried out regardless of the phases of the menstrual cycle. A small mathematical model of glucose homeostasis (Homeostasis Model Assessment-HOMA) was used to assess the degree of insulin resistance. The study of calorie and nutritional balance was carried out using a nutrition diary with daily self-control and doctor's control, initially after 2 weeks, and then every month.

\section{Statistical Analysis}

Statistical processing of the results was carried out using the application package Excel 2000, Statistica 6.0. For each feature in the compared groups, the arithmetic mean value $(\mathrm{M})$ and the mean square deviation of the samples $(\sigma)$ were determined. The distribution of parameters in the groups was visualized using the corresponding frequency histograms. The hypothesis of equality of general 
means in the two compared groups was tested using the nonparametric MannWhitney U-test for independent samples. When comparing indicators in three or more independent groups, analysis of variance was used analysis of variance (non-parametric Kruskal-Wallis method) followed by pairwise posterior comparison of groups. To assess the significance of changes in symptoms in patients during treatment, the Wilcoxon $\mathrm{W}$-test was used for dependent samples. Comparison of the general fractions (frequencies) was carried out using analysis of contingency tables (according to the $\chi^{2}$ criterion). The study of the relationship between quantitative traits was carried out using the Spearman rank correlation coefficient (r). As a method of mathematical modeling, cluster analysis was used to search for unknown patterns of relationship of signs. The study of the relationship between quantitative traits was carried out using the Spearman rank correlation coefficient (r). As a method of mathematical modeling, cluster analysis was used to search for unknown patterns of relationship of signs. The significance of the parameters in the distribution of cases (observations) by groups was evaluated using the Fisher F-test. The null hypothesis was rejected in all cases at a critical significance level of $\mathrm{p}<0.05$.

\section{Results}

Twenty $(87 \%)$ of the 23 women included in the study completed the treatment protocol. 3 patients dropped out of the study due to non-compliance with the diet regimen. These patients required the appointment of additional drug therapy. A decrease in body weight from 4 to $24 \mathrm{~kg}$ was found in all patients who completed the protocol by an average of $10.58 \pm 5.70 \mathrm{~kg}(\mathrm{p}<0.001)$. The dynamics of the main anthropometric indicators in the examined patients, against the background of diet therapy, are presented in Table 1.

The results of the study also showed that in study participants, against the background of diet therapy, there was a statistically significant decrease in BMI from $32.53 \pm 1.40$ to $28.55 \pm 2.50$ ( $\mathrm{p}<0.001$ ). Waist circumference (WC) for 12 months of diet therapy decreased on average by $9 \mathrm{~cm}$, from $94.18 \pm 7.15 \mathrm{~cm}$ to $85.05 \pm 8.86 \mathrm{~cm}(\mathrm{p}<0.001)$, Hip circumference HC $(\mathrm{cm})$ also decreased from $114.90 \pm 4.99$ to $106.85 \pm 5.61, \mathrm{p}<0.001$ in addition, the $\mathrm{WC} / \mathrm{HC}$ ratio decreased from 0.82 to 0.79 ( $\mathrm{p}<0.001)$. A statistically significant decrease in the volume of adipose tissue was recorded both due to subcutaneous and visceral fat and other indices $\mathrm{p}<0.001)$. Indicators of hormonal and metabolic status against the background of ongoing diet therapy in infertile obese women are presented in Table 2 .

In the dynamics when using diet therapy in infertile obese patients with a decrease in body weight, a statistically significant decrease in leptin levels of 1.8 times $(\mathrm{p}<0.001), \mathrm{E}_{1}(\mathrm{p}=0.049), \mathrm{E}_{2}(\mathrm{p}=0.032)$ and an increase in progesterone content $(\mathrm{p}=0.030)$, which indicates the restoration of the ovulatory menstrual cycle. There was a statistically significant decrease in fasting glycemia ( $\mathrm{p}<$ 0.001 ), the insulin resistance HOMA-IR decreased by 1.3 times ( $p=0.002$ ). Normalization of the blood lipid spectrum was noted: a decrease in the level of 
Table 1. Change in anthropometric indicators and indicators of volumes and mass of adipose tissue in infertile women of reproductive age with obesity against the background of diet therapy $(n=20)$.

\begin{tabular}{cccc}
\hline Parameters & Before treatment & After treatment & P \\
\hline Weight $(\mathrm{kg})$ & $85.15 \pm 8.62$ & $75.10 \pm 9.28$ & $<0.001$ \\
BMI $\left(\mathrm{kg} / \mathrm{m}^{2}\right)$ & $32.53 \pm 1.40$ & $28.55 \pm 2.50$ & $<0.001$ \\
Waist circumference WC (cm) & $94.18 \pm 7.15$ & $85.05 \pm 8.86$ & $<0.001$ \\
Hip circumference HC (cm) & $114.90 \pm 4.99$ & $106.85 \pm 5.61$ & $<0.001$ \\
WC/HC & $0.82 \pm 0.06$ & $0.79 \pm 0.07$ & $<0.001$ \\
Sagittal diameter (cm) & $23.85 \pm 1.18$ & $19.68 \pm 2.01$ & $<0.001$ \\
Volume of total adipose fat tissue (VTAT), 1 & $29.0 \pm 4.61$ & $21.07 \pm 5.44$ & $<0.001$ \\
Volume of visceral adipose tissue (VVAT), 1 & $5.95 \pm 0.92$ & $2.93 \pm 1.36$ & $<0.001$ \\
Volume of subcutaneous adipose tissue (VSAT), 1 & $23.09 \pm 4.12$ & $18.09 \pm 4.64$ & $<0.001$ \\
Mass of total adiposetissue (MTAT), kg & $26.77 \pm 4.25$ & $19.45 \pm 5.02$ & $<0.001$ \\
Fat-free mass (FFM), kg & $58.34 \pm 4.71$ & $56.14 \pm 4.19$ & $<0.001$ \\
\hline
\end{tabular}

Table 2. Dynamics of hormonal and metabolic parameters in infertile women of reproductive age with obesity on the background of diet therapy $(n=20)$.

\begin{tabular}{cccc}
\hline Parameters & Before treatment & After treatment & P \\
\hline FSH, IU/mL & $4.82 \pm 1.34$ & $5.04 \pm 1.35$ & 0.220 \\
LH, IU/mL & $5.05 \pm 1.55$ & $4.67 \pm 1.16$ & 0.211 \\
LH/FSH & $1.17 \pm 0.52$ & $1.09 \pm 0.67$ & 0.062 \\
Immune-reactive Insulin, mIU/L & $11.96 \pm 4.92$ & $10.07 \pm 4.90$ & 0.054 \\
Leptin, ng/ml & $56.32 \pm 14.84$ & $32.84 \pm 15.11$ & $<0.001$ \\
E, pmol/1 & $716.13 \pm 457.88$ & $575.54 \pm 383.90$ & 0.049 \\
E , pmol/1 & $97.00 \pm 43.08$ & $80.44 \pm 25.86$ & 0.032 \\
Testosterone, nmol/1 & $1.73 \pm 0.80$ & $1.75 \pm 0.77$ & 0.860 \\
Progesterone, nmol/1 & $18.97 \pm 13.52$ & $25.33 \pm 11.99$ & 0.030 \\
Fasting blood sugar (FBS), mmol/1 & $4.82 \pm 0.64$ & $4.25 \pm 0.53$ & $<0.001$ \\
2 hours FBS, mmol/1 & $5.04 \pm 0.94$ & $4.86 \pm 0.65$ & 0.289 \\
HOMA-IR & $2.61 \pm 1.06$ & $1.92 \pm 0.95$ & 0.002 \\
Cholesterol, mmol/1 & $5.39 \pm 0.80$ & $4.81 \pm 0.83$ & $<0.001$ \\
Triglycerides, mmol/1 & $1.56 \pm 0.62$ & $1.19 \pm 0.53$ & 0.004 \\
HDL, mmol/1 & $1.31 \pm 0.48$ & $1.52 \pm 0.51$ & 0.092 \\
LDL, mmol/1 & $3.41 \pm 0.66$ & $2.61 \pm 0.82$ & 0.001 \\
Atherogenic Index plasma (AIP) & $3.74 \pm 1.67$ & $2.39 \pm 0.91$ & $<0.001$ \\
\hline
\end{tabular}

cholesterol $(\mathrm{p}<0.001)$, TG $(\mathrm{p}=0.004)$, LDL cholesterol $(\mathrm{p}=0.001)$, and Ka $(\mathrm{p}$ $<0.001)$. When included in the study, $9(45 \%)$ patients complained of menstrual irregularities (oligomenorrhea), 12 months after treatment, menstrual irregulari- 
ties were absent in all women $(\mathrm{p}=0.002)$. The biphasic ovulatory menstrual cycle recovered in all women, the desired pregnancy within a year occurred in 1 patient.

\section{Discussion}

The results of the study showed that in women with a gluteofemoral type of obesity (BMI of $30-34.9 \mathrm{~kg} / \mathrm{m}^{2}$ ), without pronounced disorders of carbohydrate and lipid metabolism, eating disorders, lack of arterial hypertension or the presence of transient arterial hypertension, minor hormonal disorders, with the presence of menstrual irregularities in a small number of cases, diet therapy in combination with a complex of physical exercises, psychotherapy and correction of eating behavior was highly effective active and allowed most of them to reduce and maintain their weight gain for 12 months to improve metabolic and hormonal indicators, normalize menstrual function, thus improving their reproductive capabilities. Our results are consistent with other reports [26].

The average loss of $10 \mathrm{~kg}$ during a 12 -month period showed significant positive effect in all parameters studied. This decrease was due to the improvements in both visceral and adipose fat tissue volumes.

Our results showed that diet therapy corrected menstrual irregularities manifested as oligomenorrhea in all our participants. Central obesity is related to an increased risk of anovulation [27]. The mechanism through which weight impairs fertility is largely unknown, it has been suggested that a lower concentration of sex hormone-binding globulin (SHBG) [27] and increased androgens, insulin secretion and insulin resistance [10] may play a major role in the development of oligomenorrhea and hence infertility.

Most importantly, the intervention resulted in the improvement of both leptin, FBS and HOMA-IR which are very important aspects of PCOS-related infertility. In addition, all lipid profile indices improved specifically the LDL levels, which is a vital issue for the future risk of cardiovascular disease, highly prevalent in obese women [28]. Moreover, our results showed that atherogenic index of plasma (AIP) which is a strong marker to predict the risk of atherosclerosis and coronary heart disease [10] has improved dramatically after low caloric diet therapy and exercise.

A study by Rashad M. et al. [29] showed that serum leptin can be a valuable diagnostic marker for obesity and its concomitant diseases. In addition, the author presents evidence that significant weight loss leads to a decrease in serum leptin levels and an improvement in glycemic and lipid profiles.

Currently, there are epidemiological studies that have shown that as soon as a woman finds out about pregnancy, she should not change her lifestyle [18]. Thus, there is no doubt the need for diet therapy at the stage of pre-conceptional preparation, there are more discussions regarding methods that will improve compliance with this method of treatment. So, currently in the Netherlands, a longitudinal randomized controlled study [30] of a one-year three-component intervention in the cognitive-behavioral lifestyle in overweight/obese women 
with PCOS is being conducted. The authors of the study expect to get a more significant effect in lifestyle modification and weight loss by $5 \%-10 \%$ during the work of the multidisciplinary team. In our study, $87 \%$ women with grade I gluteofemoral obesity completed the protocol and demonstrated good motivation and high compliance with diet therapy, which was accompanied by adequate physical activity and behavioral therapy. Only 3 out of 23 patients required medication.

Despite the obvious evidence of the need to reduce body weight at the stage of pregnancy planning, the nature of nutrition at the preconception stage and during pregnancy in obese people is widely discussed. For example, a study by $\mathrm{H} \mathrm{Al}$ Wattar B. [31] showed that a simple Mediterranean diet does not reduce the overall risk of adverse maternal and perinatal outcomes, with the exception of large weight gain during pregnancy and gestational diabetes. However, to date, not a single randomized controlled trial has demonstrated effective means of weight loss, which lead to improved pregnancy outcomes for both mother and baby. An ZCTR study is currently registered in Australia, which aims to determine the best approach to weight loss during pregnancy planning [32] The study will include 164 patients with a BMI of $30-55 \mathrm{~kg} / \mathrm{m}^{2}$. Patients will be divided into two groups: the first-patients in whom a slight decrease in body weight by $3 \%-5 \% \mathrm{~s}$ is planned using a moderately hypocaloric diet for 12 months, the second-patients who are planning a significant reduction in body weight by $10 \%-15 \%$ using a modified pronounced low-energy diet [32].

In addition, according to van Elten TM [33], the preconception period may be the best window of opportunity for improving lifestyle in general. So in a randomized controlled trial conducted by these authors, it was shown that lifestyle changes that were at the stage of pregnancy planning in infertile women, diet, restriction of high-calorie food intake, physical activity persisted after 5.5 years (range $=3.7-7.0$ years) after the intervention. In a study by Wekker V. et al. [34], two RCTs were analyzed, where women were also observed after changing their lifestyle in the preconception period. Women who successfully lost weight during preconception training had better cardio-metabolic health after 6 years, which once again emphasizes the potential for improving lifestyle before conception.

One of the main weaknesses of this study is the relatively small number of participants. However, the main strengths are the fact that it is one of few papers that combined low fat diet and exercise to maximize the final effect and compressively explored biometric and hormonal dynamics before and after intervention.

In conclusion, the implementation of balanced hypocaloric diet for 12 months in infertile women with gluteofemoral obesity of the first degree contributes to the normalization of metabolic processes, weight loss and, in $100 \%$ of cases, the restoration of the ovulatory menstrual cycle and should be recommended to all women with infertility and obesity. 


\section{Acknowledgements}

The authors thank all patients participated in this study.

\section{Conflicts of Interest}

The authors declare no conflicts of interest regarding the publication of this paper.

\section{References}

[1] Van Dammen, L., et al. (2019) The Effects of a Pre-Conception Lifestyle Intervention in Women with Obesity and Infertility on Perceived Stress, Mood Symptoms, Sleep and Quality of Life. PLOS ONE, 14, e0212914.

https://doi.org/10.1371/journal.pone.0212914

[2] Morales Camacho, W.J., et al. (2019) Childhood Obesity: Etiology, Comorbidities and Treatment. Diabetes/Metabolism Research and Reviews, e3203. https://doi.org/10.1002/dmrr.3203

[3] Rumińska, M., et al. (2015) Cardiovascular Risk Factors in Obese Children and Adolescents. In: Pokorski, M., Ed., Advances in Clinical Science, Springer, Amsterdam, 39-47. https://doi.org/10.1007/5584_2015_168

[4] Gante, I., Amaral, N., Dores, J. and Almeida, M.C. (2015) Impact of Gestational Weight Gain on Obstetric and Neonatal Outcomes in Obese Diabetic Women. BMC Pregnancy and Childbirth, 15, 249.

https://doi.org/10.1186/s12884-015-0692-Z

[5] Артымук, Н., Тачкова, О. and Шурыгин, С. (2018) Порочный репродуктивный круг. ожирения: обзор литературы.

[6] Ryckman, K.K., Borowski, K.S., Parikh, N.I. and Saftlas, A.F. (2013) Pregnancy Complications and the Risk of Metabolic Syndrome for the Offspring. Current Cardiovascular Risk Reports, 7, 217-223. https://doi.org/10.1007/s12170-013-0308-y

[7] Papachatzi, E., et al. (2015) Prepregnancy Maternal Obesity and Fetal-Perinatal Death in a Mediterranean Country. Journal of Perinatal Medicine, 43, 291-298. https://doi.org/10.1515/jpm-2014-0044

[8] Sellayah, D., Thomas, H., Lanham, S.A. and Cagampang, F.R. (2019) Maternal Obesity during Pregnancy and Lactation Influences Offspring Obesogenic Adipogenesis but Not Developmental Adipogenesis in Mice. Nutrients, 11, 495. https://doi.org/10.3390/nu11030495

[9] Brown, T., et al. (2019) Interventions for Preventing Obesity in Children. Cochrane Database of Systematic Reviews.

[10] Al-Jefout, M., Alnawaiseh, N. and Al-Qtaitat, A. (2017) Insulin Resistance and Obesity among Infertile Women with Different Polycystic Ovary Syndrome Phenotypes. Scientific Reports, 7, Article No. 5339. https://doi.org/10.1038/s41598-017-05717-y

[11] Luque-Ramirez, M., et al. (2007) Increased Body Iron Stores of Obese Women with Polycystic Ovary Syndrome Are a Consequence of Insulin Resistance and Hyperinsulinism and Are Not a Result of Reduced Menstrual Losses. Diabetes Care, 30 , 2309-2313. https://doi.org/10.2337/dc07-0642

[12] Pasquali, R. and Venturoli, S. (1986) Hyperandrogenism, Hyperinsulinism and Polycystic Ovarian Disease. Journal of Endocrinological Investigation, 9, 531-533. https://doi.org/10.1007/BF03346983 
[13] Shehadeh, N. and Ish-Shalom, S. (1990) Hyperinsulinism and Hyperandrogenism in Polycystic Ovarian Disease. Harefuah, 118, 712-713.

[14] Sozen, I. and Arici, A. (2000) Hyperinsulinism and Its Interaction with Hyperandrogenism in Polycystic Ovary Syndrome. Obstetrical \& Gynecological Survey, 55, 321-328. https://doi.org/10.1097/00006254-200005000-00026

[15] Nestler, J.E., et al. (1998) Insulin Stimulates Testosterone Biosynthesis by Human Thecal Cells from Women with Polycystic Ovary Syndrome by Activating Its Own Receptor and Using Inositolglycan Mediators as the Signal Transduction System. The Journal of Clinical Endocrinology \& Metabolism, 83, 2001-2005. https://doi.org/10.1210/jc.83.6.2001

[16] Al-Jefout, M., Al-Qtaitat, A., Al-Rahal, D., Al-Nawaiseh, N. and Rawashdeh, F. (2018) Endometrial Thickness as a Predictor of Endometrial Hyperplasia in Infertile Patients with Polycystic Ovary Syndrome. Open Journal of Obstetrics and Gynecology, 8, 92-104. https://doi.org/10.4236/ojog.2018.82012

[17] Legro, R.S., et al. (2002) Insulin Resistance in the Sisters of Women with Polycystic Ovary Syndrome: Association with Hyperandrogenemia Rather than Menstrual Irregularity. The Journal of Clinical Endocrinology \& Metabolism, 87, 2128-2133. https://doi.org/10.1210/jcem.87.5.8513

[18] Артымук, Н.В., Кондратьева, Т.А. and Тачкова, О.А. (2009) Принципы терапии пациенток с бесплодием и недостаточностью лютеиновой фазы менструального цикла. Вопросы гинекологии, акушерства и перинатологии, 8, 31-35.

[19] Maffeis, C. and Morandi, A. (2017) Effect of Maternal Obesity on Foetal Growth and Metabolic Health of the Offspring. Obesity Facts, 10, 112-117. https://doi.org/10.1159/000456668

[20] Cohen, J.B. and Gadde, K.M. (2019) Weight Loss Medications in the Treatment of Obesity and Hypertension. Current Hypertension Reports, 21, 16. https://doi.org/10.1007/s11906-019-0915-1

[21] Paccosi, S., Cresci, B., Pala, L., Rotella, C.M. and Parenti, A. (2019) Obesity Therapy: How and Why? Current Medicinal Chemistry. https://doi.org/10.2174/0929867326666190124121725

[22] Sim, K., Partridge, S. and Sainsbury, A. (2014) Does Weight Loss in Overweight or Obese Women Improve Fertility Treatment Outcomes? A Systematic Review. Obesity Reviews, 15, 839-850. https://doi.org/10.1111/obr.12217

[23] Тачкова, О., Артымук, Н. and Сутурина, Л. (2018) Случай беременности и родов после хирургического лечения ожирения. Фундаментальная и клиническая медицина, 3.

[24] WHO (2012) Global Health Observatory. Mean Body Mass Index.

[25] Klimov, A., Shestov, D.B., Triufanov, V.F., Alksnis, E.G. and Teriukova, N.P. (1984) Age and Dynamics of the Chief Blood Lipid Indices among the Adult Population of Leningrad. Kardiologiia, 24, 56-62.

[26] Crosignani, P.G., et al. (2003) Overweight and Obese Anovulatory Patients with Polycystic Ovaries: Parallel Improvements in Anthropometric Indices, Ovarian Physiology and Fertility Rate Induced by Diet. Human Reproduction, 18, 1928-1932. https://doi.org/10.1093/humrep/deg367

[27] Clark, A., Thornley, B., Tomlinson, L., Galletley, C. and Norman, R.J. (1998) Weight Loss in Obese Infertile Women Results in Improvement in Reproductive Outcome for All Forms of Fertility Treatment. Human Reproduction, 13, 1502-1505. https://doi.org/10.1093/humrep/13.6.1502

[28] Wilson, P.W., et al. (2002) Overweight and Obesity as Determinants of Cardiovas- 
cular Risk: The Framingham Experience. Archives of Internal Medicine, 162, 1867 1872. https://doi.org/10.1001/archinte.162.16.1867

[29] Rashad, N.M., Sayed, S.E., Sherif, M.H. and Sitohy, M.Z. (2019) Effect of a 24-Week Weight Management Program on Serum Leptin Level in Correlation to Anthropometric Measures in Obese Female: A Randomized Controlled Clinical Trial. Diabetes \& Metabolic Syndrome: Clinical Research \& Reviews, 13, 2230-2235. https://doi.org/10.1016/j.dsx.2019.05.027

[30] Jiskoot, G., et al. (2017) A Three-Component Cognitive Behavioural Lifestyle Program for Preconceptional Weight-Loss in Women with Polycystic Ovary Syndrome (PCOS): A Protocol for a Randomized Controlled Trial. Reproductive Health, 14, 34. https://doi.org/10.1186/s12978-017-0295-4

[31] Al Wattar, B.H., et al. (2019) Mediterranean-Style Diet in Pregnant Women with Metabolic Risk Factors (ESTEEM): A Pragmatic Multicentre Randomised Trial. PLoS Medicine, 16, e1002857. https://doi.org/10.1371/journal.pmed.1002857

[32] Price, S., et al. (2018) Health Consequences for Mother and Baby of Substantial Pre-Conception Weight Loss in Obese Women: Study Protocol for a Randomized Controlled Trial. Trials, 19, 248. https://doi.org/10.1186/s13063-018-2615-6

[33] Van Elten, T., et al. (2019) Preconception Lifestyle Intervention Reduces Long Term Energy Intake in Women with Obesity and Infertility: A Randomised Controlled Trial. International Journal of Behavioral Nutrition and Physical Activity, 16, 3. https://doi.org/10.1186/s12966-018-0761-6

[34] Wekker, V., et al. (2018) Long-Term Effects of a Preconception Lifestyle Intervention on Cardiometabolic Health of Overweight and Obese Women. European Journal of Public Health, 29, 308-314. https://doi.org/10.1093/eurpub/cky222 